\title{
MECHANISMS OF CUTTING BLADE WEAR AND THEIR INFLUENCE ON CUTTING ABILITY OF THE TOOL DURING MACHINING SPECIAL ALLOYS
}

\author{
Tomáš Zlámal', Jana Petrů1', Ondřej Vortel', Marek Pagáč', Pavel Krajkovič \\ 1 Department of Machining, Assembly and Engineering Metrology, Faculty of Technical Engineering, VSB- \\ Technical University of Ostrava, 17 Listopadu 15/2172, 70833 Ostrava-Poruba, Czech Republic, e-mail: tomas. \\ zlamal@vsb.cz
}

Received: 2016.06.04

Accepted: 2016.07.05

Published: 2016.09.01

\begin{abstract}
With increased requirements for quality and shelf life of machined parts there is also a higher share of the use of material with specific properties that are identified by the term "superalloys". These materials differ from common steels by mechanical and physical properties that cause their worse machinability. During machining of "superalloys" worse machinability has negative influence primarily on the amount of cutting edge wear, which shortens durability of the cutting tool. The goal of experimental activity shown in this contribution is to determine individual mechanisms of the cutting edge wear and their effects on the cutting ability during high speed machining of nickel superalloy. A specific exchangeable cutting insert made from cubic boric nitride was used for machining of the 625 material according to ASM 5666F. The criteria to evaluate cutting ability and durability of the cutting tool became selected parameters of surface integrity and quality of the machined surface.
\end{abstract}

Keywords: mechanisms of the wear; machining; exchangeable cutting insert; cubic boric nitride; nickel alloy; abrasive wear

\section{INTRODUCTION}

We encounter the term wear most often in machine parts that are in contact with each other or there is a movement between them. Very intensive wear happens during chip machining, during which the tool and machined workpiece are in contact, and the material leaves the front of the tool over its rake plane in a form of a chip. In this case the wear process is very complicated one that depends mainly on mechanical and physical properties of machined workpiece and tool material, tool geometry, kinematics of cutting process and effects of cutting environment. During machining there is mutual abrasion of elementary particles of boundary touching layers of cutting elements and removal of tool cutting part elements. A complete wear is given by the total of abrasion, plastic deformation and brittle breakage that are demonstrations of mechanical, heat, chemical and abrasion effects, invoked by a powerful action of a tool cutting wedge on the machined-away layer of material. Individual mechanisms of wear that decrease cutting ability and durability of the tool occur due to the loads on the tool cutting edge $[1,2]$.

Although tool wear is an integral part of cutting process, it has been partially eliminated by suitable modification of cutting conditions and geometry of the cutting tool. However, new trends in chip machining, increasing demands on quality of machined parts, their dependability and service life are the cause of development and use of new materials with specific properties. These materials are commonly called "superalloys", due to the fact that their specific properties predestine them for the most demanding machine applications. On the other hand, mechanical and physical properties of superalloys that they have due to their chemical composition and micro structure largely influence their machinability. This worsened machinability results in higher loads on tool cutting 


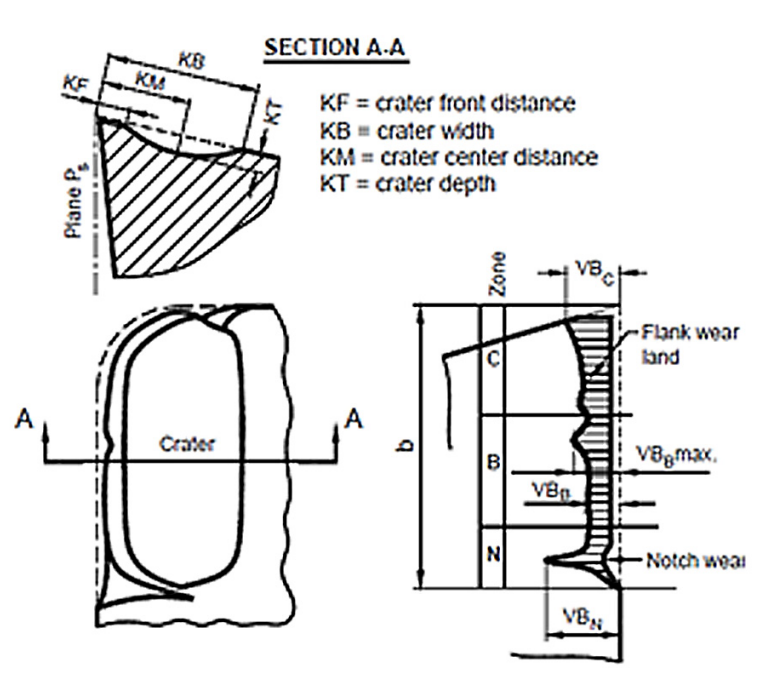

Fig. 1. Tool wears according to ISO 3685:1993 [5]

wedges and their faster wear. Therefore, the effort to find the way, how to machine these alloys easily and effectively without intensive wear of the cutting tool edge, still continues $[2,3,4]$.

\section{MECHANISMS AND CRITERIA OF TOOL WEAR DURING MACHINING}

The whole process of tool edge wear is very complicated and most often it occurs through combination of loading factors, e.g. mechanical loading or large amount of heat that accumulates on the flank and rake of the cutting tool. Heat loads significantly stress tool edge material and in some cases (for example milling) create a dynamic factor at the moment when one cutting edge leaves the material and enters it again. In article Resistance of Sintered Carbide Materials against Heat Shocks Induced by Cutting Process
(J. Petrů, J. Petřkovská, T. Zlámal, I. Mrkvica) were solved problematics focused on evaluation of cutting edge insert resistance against heat waves during milling process of stainless steel 1.4301 (X5CrNi18-10). Machined surface that has a tendency to chemical reactions or diffusion processes is created continually by the process of chip creation during high pressure and temperature. Most machined materials contain hard particles of different kind. These particles often reach hardness of the cutting tool edge material. This creates grinding or abrasive effect. Combination of mechanical, chemical and abrasive factors impose a load on the cutting tool edge, which most often results in a change of its characteristic dimension or loss of weight of the tool cutting part. At present the ISO 3685:1193 standard generally describes external manifestations of wear, therefore is more realistic to define flank wear VB, crater depth $\mathrm{KT}$, radial wear of the $\mathrm{KV} \gamma$ tool tip and others depending on the material of cutting tool edge [3-8].

\section{ANALYSIS OF THE PRESENT STATE OF ALLOY 625 MACHINING}

The Alloy 625 material according to ASM $5666 \mathrm{~F}$ is completely alloyed alloy based on $\mathrm{Ni}$, whose mechanical and physical properties are directly related to the material micro structure. Microstructure of the Nickel Alloy 625 alloy consists of two phases, namely the primary austenitic FCC matrix called $\gamma$, and the secondary precipitation phase $\gamma^{\prime \prime}[\mathrm{Ni} 3(\mathrm{Nb}, \mathrm{Al}, \mathrm{Ti})]$ that, together with solid carbides included in the material structure prevent movement of dislocations through the micro structure, are the main mechanisms of

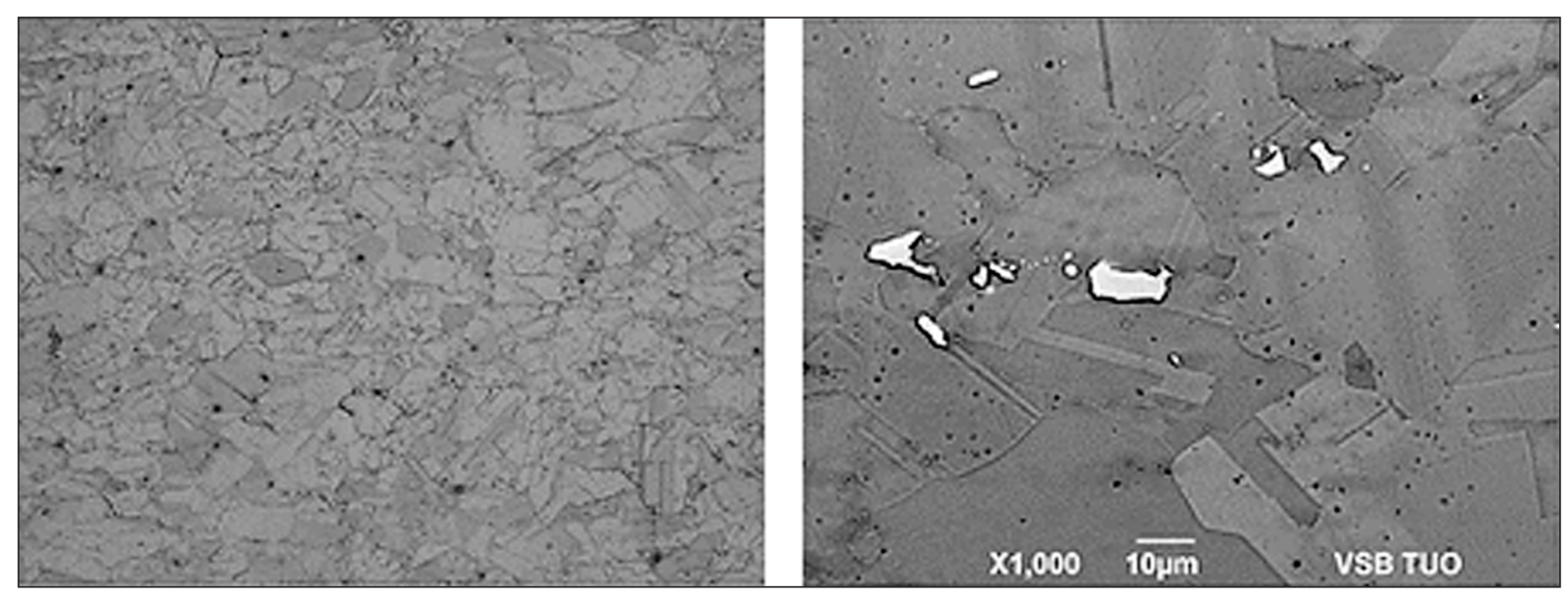

Fig. 2. Alloy 625 according to ASM 566F material structure (primary phase and MC carbides) 


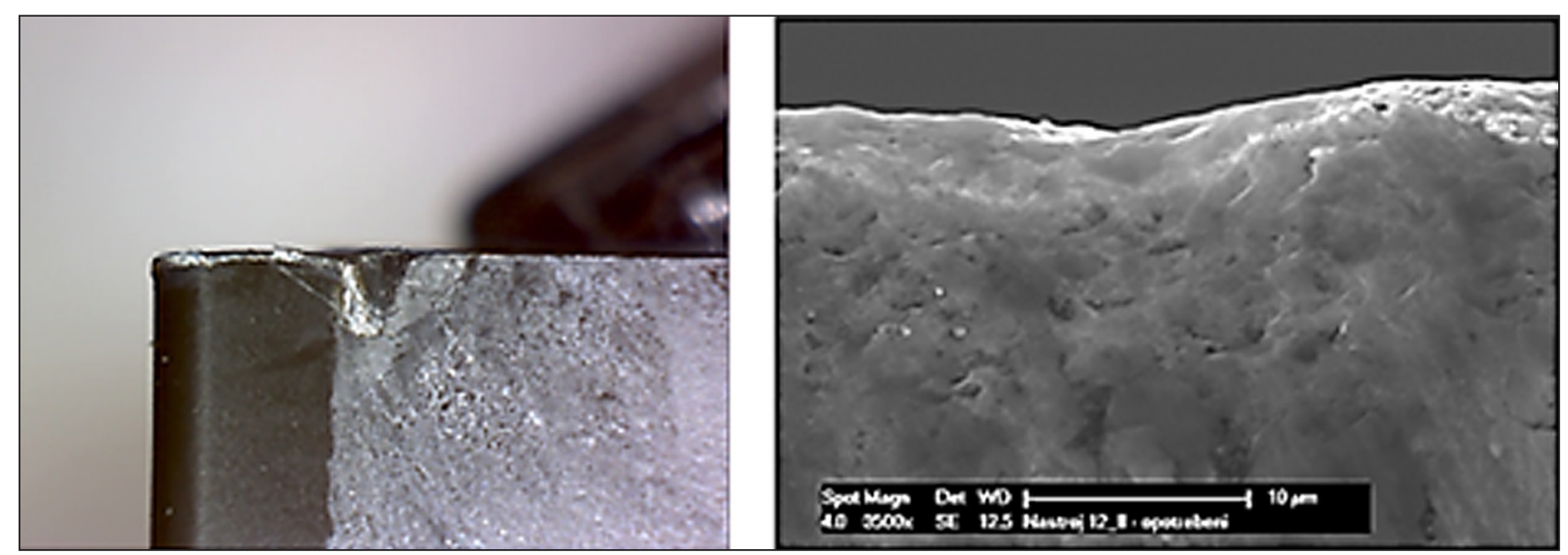

Fig. 3. Flank wear of cutting insert made from coated sintered carbide $\left(a_{p}=2.5 \mathrm{~mm} ; \mathrm{v}_{c}=50 \mathrm{~m} \cdot \mathrm{min}^{-1} ; \mathrm{f}=0.3 \mathrm{~mm}\right)$

hardening of the material surface during machining. Thus hardened material affects durability of the machining tool and causes defective surface quality, subsurface metallurgic damages, for example re-crystallization, changes in micro-hardness and remainder tensions [9].

Without regard to the particular cutting process, small amount of cut material is recommended for machining of Alloy 625. The cutting tool edge is exposed to high mechanical and heat loads that significantly influence its wear and durability. The tool is intensely damaged due to wear of the tool flank. The wear is characteristic by creation of build-up and its breaking off, deformation of cutting edge and occurrence of a groove on the flank in the location where the tool leaves the cut, see Figure 3. The creation of the notch at the flank at the location of tool exit from the stroke is primarily caused by cutting edge that in this location bites into a layer of strengthened material, whose mechanical properties are significantly different from the basic material. Presence of very hard carbides contained in the structure and border of grains causes abrasive wear and very quick creation of notches on the rake face of the tool. Bad heat conductivity of the Alloy 625 material $\left(12.56 \mathrm{~W} \cdot \mathrm{m}^{-1} \mathrm{~K}^{-1}\right)$ can, during machining by sintered tools, cause concentration of heat in the location of cut and its increase up to the value of $1200^{\circ} \mathrm{C}$. Such high temperature represents a large problem for both ceramic tools and for oxide or nitride layers. In the sintered carbide tools this high temperature can induce excessive diffusion and thus loss of strength. During machining of Nickel alloys by sintered carbides the recommended range of cutting speeds is 10 to $30 \mathrm{~m} \cdot \mathrm{min}^{-1}$. However, the current trend to improve cutting conditions uses multiple layers deposited on the tools by the PVD method cladding. Cladding by multiple layers (TiN+TiCN+TiN) allows reaching cutting speeds of up to $50 \mathrm{~m} \cdot \mathrm{min}^{-1}[2,3]$.

Alloys based on Nickel have a large chemical affinity to many tool materials and additionally they create adhesive layers on their surfaces that cause diffusion and abrasive wear of the tool. Additionally, these alloys are very sensitive to the speed of deformation and very easily are deformationally hardened, which causes additional excessive wear of the tool, especially on the rake and flank plane of the tool. The predominant way of wear in sintered carbides is a serious flank wear of the cutting tool and creation of notches at the tool tip. High cutting speed cannot be used during machining of nickel alloys, since the tools made from sintered carbides badly resist to extremely high temperatures and tension states that are present in the location of cut. Creation of notches at the tool tip rapidly increases at high cutting speeds. This usually results in premature breakage of the whole edge, see Figure $4[2,3,10]$.

The creation of the notch at the flank at the location of tool exit from the stroke is primarily caused by cutting edge that in this location bites into a layer of strengthened material, whose mechanical properties are significantly different from the basic material. It is assumed that creation of the notch at the flank plane is caused by sticking of machined off material to the cutting edge with the follow-up tearing of the tool material. An accompanying process is creation of burrs in this location, so the machined off material is pushed in rake face of the cutting tool, which is characteristic for machining of nickel alloys by low cutting speeds. In higher cutting speeds above $120 \mathrm{~m} \cdot \mathrm{min}^{-1}$ and application of tools made from 


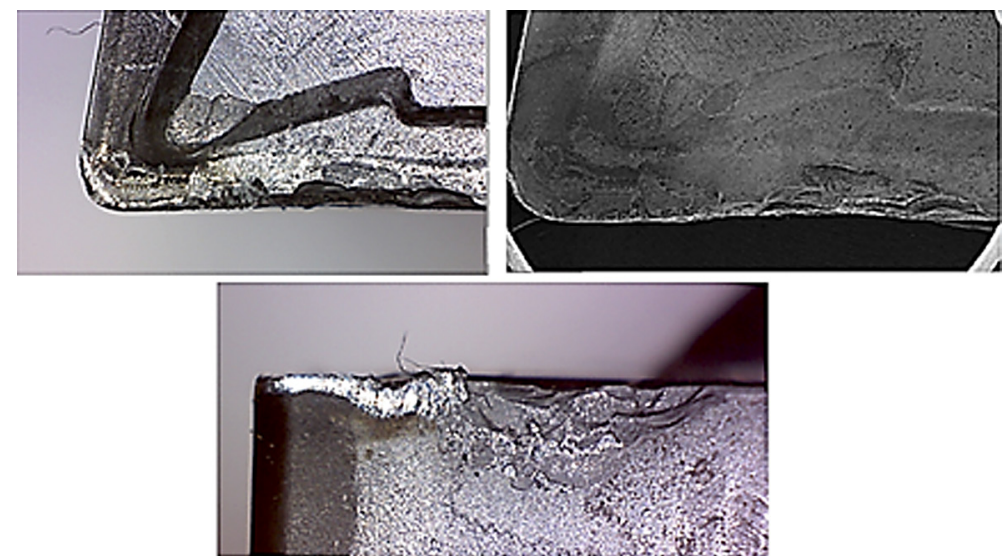

Fig. 4. Fracture of insert made from coated sintered carbide $\left(a_{p}=2.5 \mathrm{~mm} ; v_{c}=50 \mathrm{~m} \cdot \mathrm{min}^{-1} ; f=0.3 \mathrm{~mm}\right)$

cutting ceramics this process is not so intensive anymore, which is primarily caused by the fact that at high cutting speeds decrease of mechanical properties due to temperature is significant. Higher temperature at the cut location does not have beneficial effects on the creation of chip only, but also on accelerated movement of dislocations in the material structure $[2,3,10]$.

\section{EXPERIMENTAL PART OF ALLOY 625 MACHINING AND DETERMINATION OF WEAR MECHANISMS OF CBN TOOL}

Other targets of experimental activities were to verify suitability of use of the CBN cutting tool for machining of Alloy 625 according to ASM $5666 \mathrm{~F}$, and to determine types and mechanisms of wear (abrasion, adhesion, oxidation diffusion, plastic deformation, etc.) and their influence on cutting ability and durability of cutting tool. Classification of individual mechanisms of CBN tool edge wear was done for the purpose of creation of database for evaluation of machining operations, and thus possibilities of influencing machining effectivity of Alloy 625. Using high microscope magnification and determination of which wear mechanisms are thus visible will allow us to monitor cutting ability and durability of the used cutting tool. The verification of suitability of CBN tool was done during longitudinal machining of Alloy 625 under cutting conditions determined by the manufacturer of the tool in advance.

\section{CUTTING TOOL MADE OF CBN}

Cubic boric nitride $(\mathrm{CBN})$, from which the exchangeable cutting insert is made, is mate- rial of extraordinarily high strength in high temperature that can be used in very high cutting speeds of $400 \mathrm{~m} \cdot \mathrm{min}^{-1}$ to $500 \mathrm{~m} \cdot \mathrm{min}^{-1}$. It is also characteristic by being very tough and resistant against heat shocks. By its properties it is very similar to cutting ceramics, but in comparison it is tougher. Due to their high hardness and resistivity against abrasion cutting tools made of CBN have outstanding resistivity against wear. Both its functional properties and resistivity against abrasion are directly related to their bonding material, their content of hard phase and grain size. Modern CBN classes are ceramic composites with the CBN content of $40-65 \%$. Ceramic binding agents increase resistivity of $\mathrm{CBN}$ tools that are otherwise prone to chemical abrasion wear. Another group is classes with high CBN content reaching from 85 to almost $100 \%$. These classes can contain metal binding agent that increases their toughness $[2,3,11,12]$.

High heat stability and resistivity of the CBN tool causes that heat generated during cutting in the area of the tool and machined workpiece plane (the area of shear plane) heats the machined workpiece material that becomes more pliable and puts up less cutting resistance. Tools made of $\mathrm{CBN}$ are primarily suitable for the area of innovative machining technologies, like high-speed machining, hard machining and machining without use of liquids.
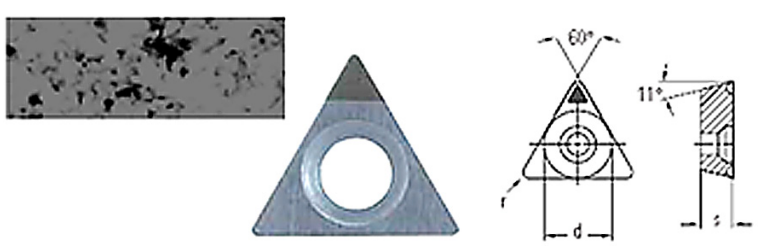

Fig. 5 Cutting tool with CBN tip (TPGX110304 D25 CBN) [14] 
CBN classes are recommended for machining of materials with hardness above $45 \mathrm{HRC}$; they are suitable primarily for machining of highly alloyed steels and special alloys that are hard to machine with commonly available tools. For materials with hardness of $55 \mathrm{HRC} \mathrm{CBN}$ is the only tool material that can substitute grinding $[3,11,13]$.

Cutting Parameters: [11]

- cutting speed, $\mathrm{v}_{\mathrm{c}}-\mathrm{mm} \cdot \mathrm{min}^{-1}\left(\mathrm{f}_{\mathrm{t}} \cdot \mathrm{min}^{-1}\right)=200$ (656),

- feed, $\mathrm{f}_{\mathrm{n}}-\mathrm{mm}$ (inch) $=0.2(0.0079)$,

- depth of cut, $a_{p}-$ mm (inch) $=0.2$ (0.0079)

\section{THE METHOD OF DETERMINATION OF CBN TOOL WEAR}

For correctly selected tool, corresponding cutting conditions, machined workpiece quality and machining conditions there is optimal progression of wear for each machining process. An exchangeable cutting insert with the $65 \% \mathrm{CBN}$ tip was selected as suitable for finish machining of high strength and toughness materials. A picture of cutting edge from scanning microscope enlarged several times was used to find and analyze mechanisms of tool wear, see Figure 6.

\section{MECHANISMS OF CBN TOOL WEAR DURING MACHINING OF ALLOY 625}

The Alloy 625 nickel alloy has very low heat conductivity, which, during machining process, causes generation of high temperature. The CBN tool also has low heat conductivity; therefore all generated heat focused itself into the cutting area and caused diffusive wear in the surface layers. The tool wear demonstrated itself by irregular grooves at the tool flank and creation of notches on the rake plane. A small chip cross-section dur-

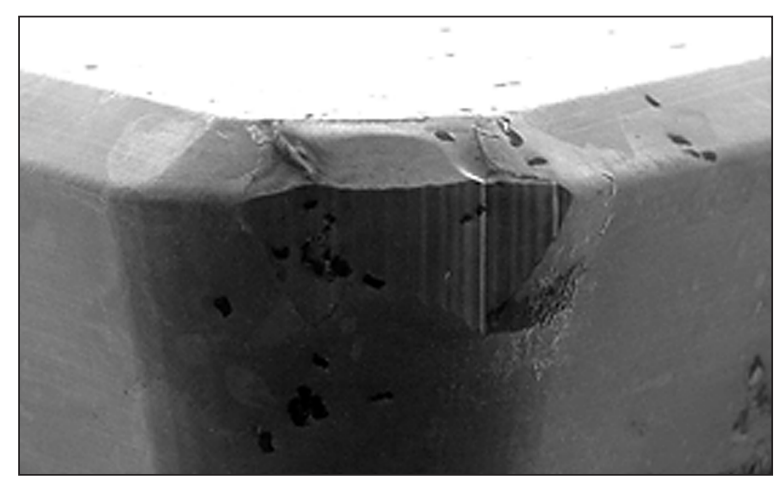

Fig. 6. Tool wear (enlarged 120x) ing machining is the reason for high heat and also mechanical load of the tool cutting edge in contact planes. There was abrasive effect and wear during increased mechanical load that was caused by friction of two contact planes. The "hard" abrasive particles contained in the machined-off material layer and primarily in the chip have the largest influence in abrasive wear. In our case they mostly were hard carbides, namely chrome and $\mathrm{MC}$ carbides contained in the Alloy 625 machined material structure. Due to the effect of abrasive wear there was gradual grinding off particles of tool material on the flank plane and partially also on the rake plane in the contact zone, see Figure 7 and 8.

Another form of wear that is typical for machining of nickel alloys is creation of a notch on the tool flank plane. Creation of a notch on the tool is usually related to the mechanism of oxidation wear and also with the contact of strengthened layer of material in the location, where the tool exits the cut. Creation of a notch was not demonstrated for the CBN tipped tool used during machining of the Alloy 625 alloy, which is a certain advantage over the tools made of coated sintered carbide. Mechanical and physical properties of machined material with

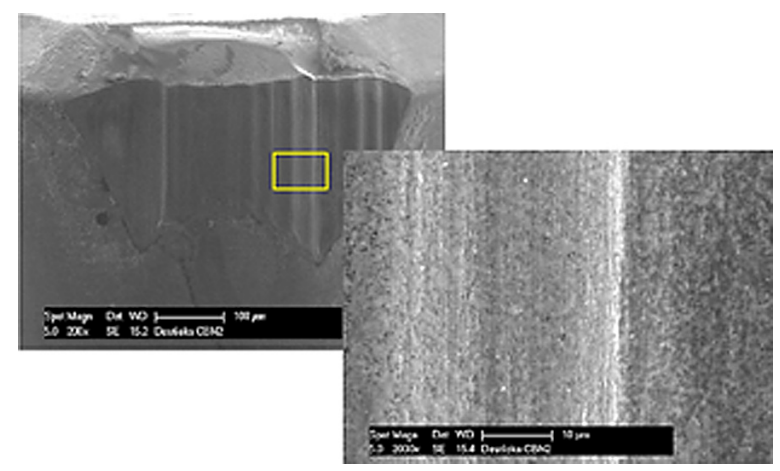

Fig. 7. Abrasive wear of the flank plane (enlarged 2000x)

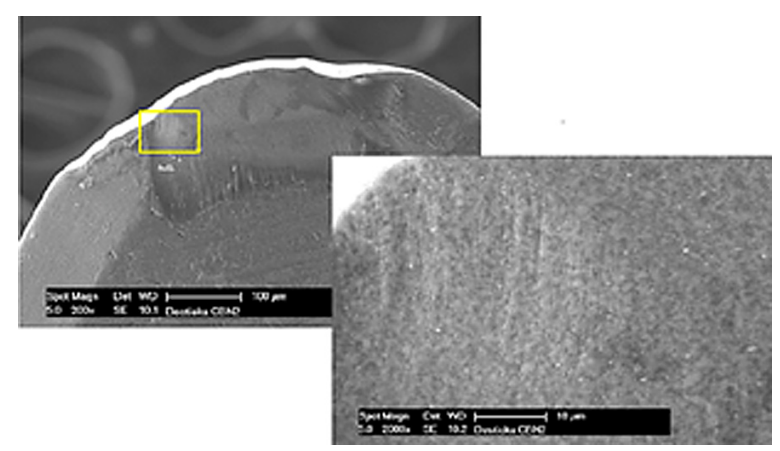

Fig. 8. Abrasive wear of the rake plane (enlarged 2000x) 

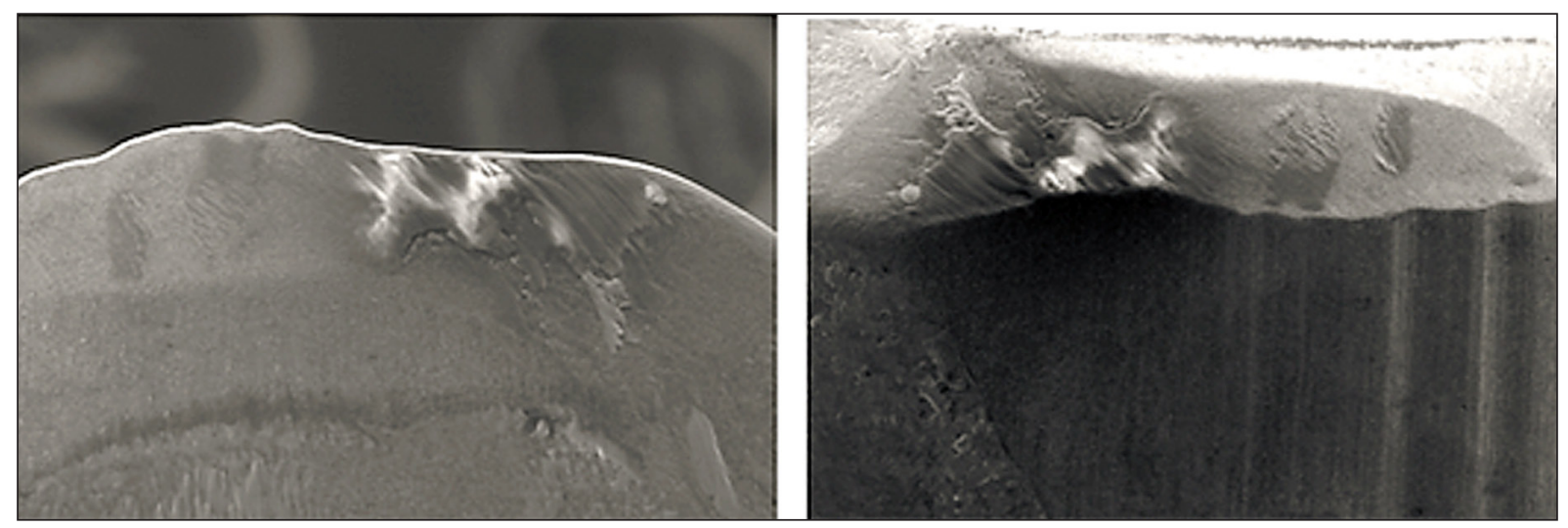

Fig. 9. Creation of a build-up on the transition plane of the tool cutting edge

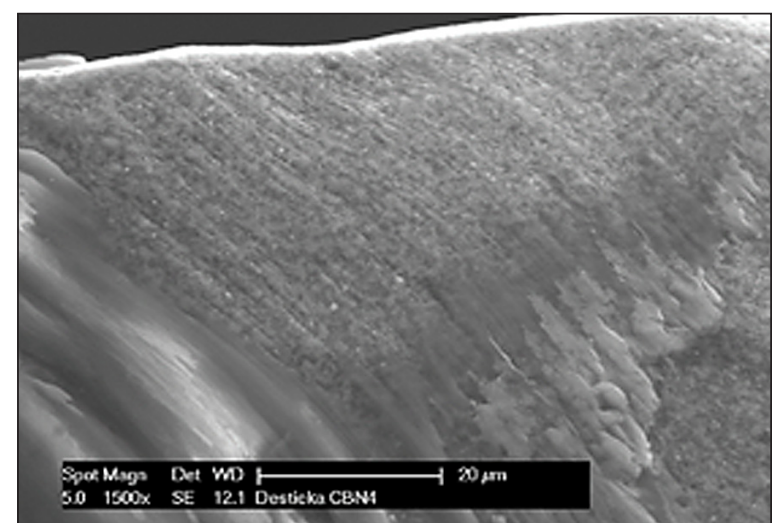

Fig. 10. Ground out layer of welded-on material (enlarged 1500x)

cutting parameters influence, to certain extent, creation of build-ups on the tool cutting edge. Since the machined material Alloy 625 is very tough, there was adhesion of machined material layers to the tool material in the contact zone during machining, see Figure 9. During creation of build-ups there is usually a change in geometry and breakage of cutting edge of the tool together with welded on build-up, in the worst case a cutting insert can fracture.

Sizes and amounts of build-ups were directly proportional to the affinity between machined material and the CBN tipped tool. However, abrasive effect of hard particles contained in the structure of machined material caused that the layer of welded-on material was gradually grinded off and with several exceptions there were no wear of the tool cutting edge by breakage of created buildups, see Figure 10.

\section{CONCLUSIONS}

From the point of view of effective machining of nickel alloys it is hard to select a correct cutting tool, to determine suitable cutting parameters or cutting environment. These alloys belong to hardto-machine materials that create articulated chip during machining, which results in the creation of large and highly dynamic cutting forces. Due to very low heat conductivity and high hardness there is creation of large amount of heat; the material easily sticks to the cutting edge and creates a build-up. The high strength, mechanical hardening and adhesion result in notch shaped wear at the maximum cut depth level, while extremely abrasive environment is created for the cutting tool edge at the same time.

During selection of the tool cutting material the determining consideration is loading of the cutting edge. High strength, toughness, high hardness while heated, good resistivity against temperature shocks, chemical stability under high temperatures of the cutting edge is primarily required. The cutting geometry must meet tool requirements for sufficient strength of cutting wedge, smooth cutting action without vibrations, and maximum tool durability.

According to presumptions an exchangeable cutting insert with $\mathrm{CBN}$ tip was proposed for the experimental activity of the Alloy 625 according to ASM 5666F nickel alloy. Tools made of CBN are primarily suitable for machining of hard-to-machine materials, because they excel by their high toughness, hardness, heat and chemical stability, good bending resistance and general resistance to wear. The goal of this experimental testing was to classify individual mechanisms of wear in order to evaluate machining operations and thus possibilities to influence effectivity of the Alloy 625 alloy machining.

The predominant mechanism of CBN tipped tool wear was the abrasive wear of the rake and also flank of the tool cutting edge. This abrasive wear oc- 
curred by the influence of hard carbides contained in the material structure and had a large effect on the total durability of the tool. The most intensive abrasive effects were in the contact zone, namely during exposure if the cutting material to the machined workpiece material, more exactly then before creation of the chip, during creation of the chip and after it. By generating of high temperatures in the location of cut there were demonstrations of diffusion wear, creation of irregular grooves on the flank plane and notches on the rake plane of the tool. Non-negligible part of wear was also creation of build-ups on the tool cutting part. However, even though there were build-ups, direct influence on the tool durability during machining of Alloy 625 was not proven. They were, just as the basic material of the tool, ground away from the surface by abrasive effects of machined-off material.

Monitoring and measuring of tool wear has been an important part of cutting process lately, since the condition of resulting machined workpiece fully depends on condition of the tool itself. Understanding of wear mechanisms and analyzing of wear types leads to correct selection of cutting tool materials, edge geometries, cutting conditions and also machined workpiece materials. With good knowledge of mechanisms and types of wear we can easily select the most effective cutting materials, correct edge geometries and conditions to secure effective machining. Experimental studies of wear and dulling of cutting edges is the base for determination of empiric data for optimization of cutting parameters or durability of the cutting edge. Considering the above mentioned reasons the tool wear is perfectly normal physical phenomenon, and it is not necessary or the goal to prevent it. However, it needs to be monitored to be safe, controllable and predictable.

\section{Acknowledgements}

Article has been done in connection with project Education System for Personel Resource of Development and Research in Field of Modern Trend of Surface Engineering - Surface Integrity, registration number CZ.1.07/2.3.00/20.0037 financed by Structural Founds of Europe Union and from the means of state budget of the Czech Republic and by project Students Grant Competition financed by the Ministry of Education, Youth and Sports and Faculty of Mechanical Engineering VŠB-TUO.

\section{REFERENCES}

1. Stahl J-E., Metal cutting - Theories and models. Sweden: Division of Production and Materials Engineering. Lund University Sweden, 2012, pp. 580.

2. Astakhov V.P., Davim J.P. Tools (Geometry and Material) and Tool Wear. Machining Fundamentals and Recent Advances, 2008, Hardcover.

3. Zajac J., Jurko J., Cep R. Top trendy v obrábaní, II čast' - Nástrojové materiály. Žilina: Media/St, s.r.o. Žilina, 2006, pp. 193.

4. Sadílek M., Kratochvíl J., Petrů J., Cep R., Zlámal T., Stančeková D.: Cutting tool wear monitoring with the use of impedance layers. Tehnicki Vjesnik, 21(3), 2014, 639-644.

5. ISO 3685:1993 (1993). Tool-life testing with single-point turning tools. Geneva, International Organization for Standardization, $48 \mathrm{p}$.

6. Valášek P., Müller M.: Abrasive wear in threephase waste based polymeric particle compo-sites. Tehnicki Vjesnik-Technical Gazette, 12(2), 2015, 257-262.

7. Müller M., Chotěborský R., Valášek P., Hloch. S.: Unusual possibility of wear resistance increase research in the sphere of soil cultivation. Tehnicki Vjesnik-Technical Gazette, 20(4), 2013, 641-646.

8. Stancekova D., Semcer J., Rudawska A., Cep R.: Identification of drilling of biocompatible materials based on titanium. Manufacturing Technology, 15(4), 2015, 699-704.

9. Shankar V., Bhanu Sankara Rao K., Mannan S.L. Microstructure and mechanical properties of Inconel 625 superalloy. Journal of Nuclear Materials, 288, 2001, 222-232.

10. Neslušan M., Czán A., Obrábanie titánových a niklových zliatin. Žilina: Žilinská univerzita v Žilině, EDIS, 2001, pp. 189.

11. Modern Metal Cutting, A practical Handbook, Sandvik Coromant.

12. INSERTS - Ingersoll Cutting Tools: [Online], [Accessed 2014-12-11] URL: http://www.ingersollimc.com/en/products/CAT-003-1_07-Inserts.pdf

13. Fulemová J., Řehoř J.: Influence of form Factor of the Cutting Edge on Tool Life during Finishing Milling. Procedia Engineering. Vídeň: Elsevier Ltd, 2015, 682-688.

14. Petrů J., Petřkovská J., Zlámal T., Mrkvica I.. Resistance of Sintered Carbide Materials against Heat Shocks Induced by Cutting Process. Proceedings METAL'2014, 23rd International Conference on Metallurgy and Materials, Brno, Czech Republic, 142-147. 